\title{
DEPENDENCE ON SOCIAL NETWORKING SITES IN ADOLESCENTS
}

\author{
Ranjith Rajeev ${ }^{1}$, Santosh Soans ${ }^{2}$, Amita Rao Aroor ${ }^{3}$, Ramgopal Shastry ${ }^{4}$, Ashvij Shriyan ${ }^{5}$ \\ 1 Post Graduate, Department of Paediatrics, AJ Institute of Medical Sciences, Mangalore. \\ 2 Professor \& HOD, Department of Paediatrics, AJ Institute of Medical Sciences, Mangalore. \\ 3Professor, Department of Paediatrics, AJ Institute of Medical Sciences, Mangalore. \\ ${ }^{4}$ Associate Professor, Department of Paediatrics, AJ Institute of Medical Sciences, Mangalore. \\ ${ }^{5}$ Senior Resident, Department of Paediatrics, AJ Institute of Medical Sciences, Mangalore.
}

\begin{tabular}{l} 
ABSTRACT \\
\hline BACKGROUND \\
Social Networking Sites (SNSs) are "web-based services" that allow individuals to: (1) Construct a public or semi-public profile \\
within a bounded system, (2) Articulate a list of other users with whom they share a connection, and (3) View and traverse their list \\
of connections and those made by others within the system." Social networking sites like Facebook, WhatsApp, Snapchat, Twitter, \\
etc. are virtual communities where users can create individual public profiles, interact with real life friends and meet other people \\
based on shared interests. Negative correlates of Social Networking Sites usage include the decrease in real life social community \\
participation and academic achievement as well as relationship problems, each of which may be indicative of potential addiction.
\end{tabular}

\section{AIMS AND OBJECTIVES}

To study and assess the dependence on social networking sites among medical college students of adolescent age group.

\section{MATERIALS AND METHODOLOGY}

200 subjects, both boys and girls were included in the cross-sectional study who were given a 20-item Young's internet addiction test modified for social networking sites. The responses were analysed using Chi square test and Fisher's exact test.

\section{RESULTS}

Of 198 students, $24.74 \%$ of them had occasional or 'frequency' problems, while $2.02 \%$ of them were experiencing severe problems due to excessive time spent using social networking sites and boys spent excessive time on internet compared to girls.

\section{CONCLUSION}

With the growth of technology and increasing popularity of social media, social networking sites have become a part and parcel of adolescent life. Though it is helping students in emotional development and connecting with friends and family, adolescents are devoting significant time to social networking on websites and are prone to become dependent to such form of online social interaction which can affect their academics and decrease real life social community participation.

\section{KEYWORDS}

Adolescents, Social Networking Sites, Smart.

HOW TO CITE THIS ARTICLE: Rajeev R, Soans S, Aroor AR, et al. Dependence on social networking sites in adolescents. J. Evolution Med. Dent. Sci. 2016;5(22):1172-1174, DOI: 10.14260/jemds/2016/272

\section{INTRODUCTION}

With the nature of cyber world around us today and how students are immersed in it, there is growing concern on how it affects them. The internet is more than just a means of seeking information. The emergence of social networking sites simplifies the whole process as they are easy to use and navigate. SNSs are "web-based services that allow individuals to: (1) Construct a public or semi-public profile within a bounded system, (2) Articulate a list of other users with whom they share a connection, and (3) View and traverse their list of connections and those made by others within the system.1" Social networking sites like Facebook, WhatsApp, Snapchat, Twitter, etc. are virtual communities where users can create

Financial or Other, Competing Interest: None.

Submission 02-02-2016, Peer Review 28-02-2016,

Acceptance 05-03-2016, Published 16-03-2016.

Corresponding Author:

Ranjith Rajeev,

Rachana Nilaya, $5^{\text {th }}$ Cross,

Shankar Matt Road, K. R. Puram,

Hassan-573201.

E-mail: ranjithrajeev.hassan@gmail.com

DOI: $10.14260 /$ jemds $/ 2016 / 272$ individual public profiles, interact with real-life friends and meet other people based on shared interests. ${ }^{2}$ Study on the attachment patterns of youngsters reveal the use of SNS for casual affiliations among more socially distant people by bridging the social gaps. ${ }^{3}$ The findings of an online survey of 131 psychology students in the US indicated that $78 \%$ used SNSs and that $82 \%$ of males and $75 \%$ of females had SNS profiles. Of those, $57 \%$ used their SNS on a daily basis. The activities most often engaged on SNSs were reading/responding to comments on their SNS page and/or posts to one's wall (Endorsed by 60\%; the "wall" is a special profile feature in Facebook, where people can post comments, pictures and links that can be responded to), sending/responding to messages/invites (14\%) and browsing friends' profiles/walls/pages (13\%). ${ }^{4}$

Further, a social capital divide was observed with teenagers (13-19 years) having larger networks of friends compared to older users (Above 60 years). Young adults, particularly adolescents tended to be unaware of just how much time they really spent on social networking sites. According to a recent poll, $22 \%$ of teenagers log on to their favourite social media site more than 10 times a day and more 
than half of adolescents log on to a social media site more than once a day. ${ }^{5}$ Seventy-five percent of teenagers now own cell phones and $25 \%$ use them for social media, $54 \%$ use them for texting and $24 \%$ use them for instant messaging. Thus, a large part of this generation's social and emotional development is occurring while on the Internet. ${ }^{6}$ Negative correlates of Social Networking Sites usage include the decrease in real life social community participation and academic achievement as well as relationship problems, each of which may be indicative of potential addiction. Recent research indicates that there are frequent online expressions of offline behaviours, such as bullying, clique-forming and sexual experimentations that have introduced problems such as cyberbullying, privacy issues and "sexting.7" Research studies show that sociability of the Internet is responsible for the excessive amount of time individuals spend having interactions via forums, online games and blogs. ${ }^{8}$ Other problems that merit awareness include Internet addiction and concurrent sleep deprivation.

\section{AIMS AND OBJECTIVES}

To study and assess the dependence on social networking sites among medical college students of adolescent age group.

\section{MATERIALS AND METHODOLOGY}

A cross-sectional study was conducted, which included 200 students (115 boys and 85 girls) studying in 1st and 2nd year MBBS of Medical College.

The subjects must be using internet either at home/hostel, places like cyber cafés or using smart phones. Dependence on social networking sites in adolescents is characterized by excessive indulgence in internet social networking adversely affecting academic and co-curricular activities as well as social and interpersonal behaviour was assessed by young's internet addiction test modified for problematic social networking use. ${ }^{9}$ Each question in the
Young's internet addiction test was asked, specifically in context of social networking sites.

Young's internet problematic use scale is a self-report questionnaire containing 20 items. The items on the instrument are scored on a 6-point severity scale with a score of one denoting rare problematic use at one extreme and five denoting 'always' a problematic use, while 0 denotes 'does not apply' to the individual question. The total global scores range from 0 to 100 . Two subjects were dropped out of the study as they were not using any social networking sites on the internet. Appropriate statistical tools and methods will be employed to calculate and compile data.

\section{RESULTS}

Out of 200 students to whom the questionnaire was prescribed, 198 completed and returned to the investigators. Only two students returned the questionnaire without completing as they were not registered to any of the socialnetwork sites.

It was found that $84 \%$ of the students were having access to internet through mobile phones (83.4\% of boys and $85.3 \%$ of girls) and rest were using internet at homes/hostel through computers.

\begin{tabular}{|c|c|}
\hline No. of Students & $\begin{array}{l}\text { Students using Internet } \\
\text { through Smart Phones }\end{array}$ \\
\hline Boys $(n=115)$ & $83.4(\mathrm{n}=96)$ \\
\hline Girls (n=83) & $85.5(n=71)$ \\
\hline Total $(n=198)$ & $84.3(n=167)$ \\
\hline \multicolumn{2}{|c|}{$\begin{array}{c}\text { Table 1: Number of students having Internet } \\
\text { Facility through Smart Phones }\end{array}$} \\
\hline
\end{tabular}

The scores were categorized into three groups; scores 20-49 (Group a) denotes average online users. It was found that $59 \%(n=117)$ of all students and $67.47 \%$ of girls students and $53 \%$ of boy student fall into this category. The difference was found to be statistically significant.

\begin{tabular}{|c|c|c|c|c|c|c|c|c|c|}
\hline Scores & $\begin{array}{c}\text { Group a } \\
(\mathbf{2 0 - 4 9 )}\end{array}$ & $\mathbf{\%}$ & $\mathbf{p}$ value & $\begin{array}{c}\text { Group b } \\
\mathbf{5 0 - 7 9 )}\end{array}$ & $\mathbf{\%}$ & $\begin{array}{c}\mathbf{p} \\
\text { value }\end{array}$ & $\begin{array}{c}\text { Group c } \\
(\mathbf{8 0 - 1 0 0 )}\end{array}$ & $\mathbf{\%}$ & $\mathbf{p}$ value \\
\hline Total 198 & $\mathbf{1 1 7}$ & $\mathbf{5 9 . 0 9}$ & $\mathbf{0 . 0 5}$ & $\mathbf{4 9}$ & $\mathbf{2 4 . 4}$ & $\mathbf{0 . 0 1}$ & $\mathbf{4}$ & $\mathbf{2 . 0 2}$ & $\mathbf{0 . 1 4}$ \\
\hline Boys 115 & 61 & 53.04 & & 36 & 31.3 & & 4 & 3.38 & \\
\hline Girls 87 & 56 & 67.47 & & 13 & 15.66 & & 0 & 0 & \\
\hline \multicolumn{3}{|c|}{ Table 2: Scores of students on Young's Internet Scale modified for Social Networking Sites } \\
\hline
\end{tabular}

Scores 50-79 (Group b) denotes that the users were experiencing occasional or frequency problems, i.e. they were either spending too much time surfing the social networking sites occasionally or were visiting the networking sites very frequently; $24.74 \%(n=49)$ of the responders fall into this category; $31.3 \%$ of boy's responders and $15.66 \%$ of girl responders belong to this category of social networking site users, while 4 out of 198 students falls into Group c (Scores 80-
100), all of which were boys. Scores 80-100 denotes significant problem and the users need to address their problematic use of social networking sites urgently, as the score indicated that those students were spending too much of their time on social networking websites and that was having serious deleterious effect onto their academic, co-curricular, social and interpersonal activities.

\begin{tabular}{|c|c|c|c|c|c|c|}
\hline N=198 & 0-12 Months & P value & 13-36 Months & P Value & >16 Months & P Value \\
\hline Boys 115 & 9 & 0.01 & 42 & 1.0 & 64 & 0.08 \\
\hline Girls 83 & 17 & 31 & & 35 & \\
\hline
\end{tabular}

Table 3: Represents the Time Duration since when the Students were using Social Networking Sites

$50 \%(n=99)$ of the total students have been using social networking sites for more than 3 years. Boys outnumber girls when it comes to the total number of months of their usage, but the difference was not statistically significant; $36.86 \%$ $(n=73)$ students were using these sites for more than a year but less than 3 years, while only $13 \%$ of the users have started using the networking sites since last 1 year.

The number of girls belonging to new users was more than boys and the difference was statistically significant. 


\section{DISCUSSION}

The results of our study shows the usage of social networking sites by adolescents studying in medical college, particularly those using smart phones who are one touch away from using internet.

Social networking sites allow adolescents to accomplish many tasks that are important to them offline like staying connected with family when away from home, staying connected with friends, making new friends, sharing pictures, exchanging ideas, etc. They also act as excellent health resources, teaching tools where information is at the finger tips.

However, because of their young age, adolescents can encounter inaccuracies during the searches and require parental involvement to be sure they are using reliable online resources, interpreting the information correctly and not becoming overwhelmed by the information they are reading. Using social media becomes a risk to adolescents more often than most adults realize. Most risks fall into the following categories: peer-to-peer; inappropriate content; lack of understanding of online privacy issues; and outside influences of third-party advertising groups, sexting etc. They can become victims of cyber bullying and online harassment. Acceptance by and contact with peers is an important element of adolescent life. The intensity of the online world is thought to be a factor that may trigger depression in some adolescents.

It was a stunning finding that only 1\% ( 2 out of 200 ) students whom the investigators approached were not using social networking sites. Even those who had not access to internet through smart phones were using social networking sites indicating the wide-spread popularity of these sites among the adolescent age group. The study confirmed that social networking sites are prominent part of social communication among adolescents and it is also clear that these sites have embedded themselves in the college culture.

They have also become a part of college student's daily life. Additionally, given that a vast majority of students (86.9\%) have been using social networking sites for over a year. The fact that almost one-quarter of the entire study group fall into Group b (Scores 50-79) indicates an alarming trait. These were the students who were experiencing frequent problems because of excessive use of social networking sites. This excessive indulgence was having impact on all aspects of their life including academic and co-curricular activities. The outdoor activities of such teenagers such as playing outdoor games, visiting friends and kin, visiting places such as amusement parks, zoo and museums and religious were affected in a negative manner.

Even more disturbing was the finding that $2 \%$ of all students from the sample belonged to Group c (Scores 80100 ), which indicate that the indulgence in these social networking sites was having very serious and significant impact on their lives and they must immediately address to the problem. Such students spend almost all of their leisure time on internet. They tend to cut-off from the real world and virtually live a 'cyber-life.' They make new relationships, interact with them, play games with them and share their intimate secrets and emotions with them, all in a virtual world of cyber space. The outdoor activities of such teenagers are almost diminished. They crave for going online even while they have more important works to do like studying for exams, completing some assignment or project work, preparing and practicing for a sports event or visiting some relative who seek their proximity and help. It is up to parents and students themselves to make sure that they keep an eye over the internet usage. Students should indulge in interactive activities with their peer group. Outdoor sports and games not only make adolescents physically fit, strong and healthier, but also give them chance to work as a team and coordinate their activities as a group. Similarly, they should participate in activities that improve their social and communication skills in real life situations.

\section{CONCLUSION}

In this era of technology, people cannot manage their routine without computers, smartphones and the Internet. While we are admiring the conveniences and advantages brought by the Internet, there is growing concern about addictive Internet usage, especially by the adolescent age group and whether this can lead to "Dependence" of social networking sites. In this study, we found that social networking sites have become a part of adolescent students' life and college. A significant number of adolescents, particularly those using smartphones and internet in home and hostel are using the social networking sites excessively to the extent of being regarded as 'dependence.' The problem being more common and more significant in boys as compared to girls. Given the extensive use of social networking sites and their impact, it may be of interest to not only researchers but to parents, teachers and other care takers of children.

\section{REFERENCES}

1. Ellison NB. Social network sites: Definition, history, and scholarship. Journal of Computer-Mediated Communication 2007;13(1):210-30.

2. Zhou SX, Thesis MS. Chinese university of Hong Kong China. Gratifications, loneliness, leisure boredom and selfesteem as predictors of SNS-game addiction and usage pattern among Chinese college students. 2010.

3. Lee DY. The role of attachment style in building social capital from a social networking site: the interplay of anxiety and avoidance. Computers in Human Behavior 2013;29(4):1499-509.

4. Kuss DJ, Griffiths MD. Online social networking and addiction-a review of the psychological literature. International journal of environmental research and public health 2011;8(9):3528-52.

5. Mahour P, Jain M. Internet surfing and related mental health problems in present scenario: a review. Indian Journal of Health and Wellbeing 2013;4(6):1299.

6. Hinduja S, Patchin JW. Offline consequences of online victimization: school violence and delinquency. Journal of school violence 2007;6(3):89-112.

7. O'Keeffe GS, Clarke-Pearson K. The impact of social media on children, adolescents, and families. Pediatrics 2011;127(4):800-4.

8. Douglas AC, Mills JE, Niang M, et al. Internet addiction: meta-synthesis of qualitative research for the decade 1996-2006. Computers in Human Behavior 2008;24(6):3027-44.

9. Young KS. Internet addiction: the emergence of a new clinical disorder. Cyber Psychology \& Behavior 1998;1(3):237-44. 